\section{B A Institute of \\ YK Business Administration \\ 六下 \\ Karachi \\ Leadership and Ideas for Tomorrow}

Business Review

Volume 8 Issue 2 July-December 2013

$7-1-2013$

\title{
A comparative study of the HR professionals' effectiveness in the banking sector of Pakistan
}

\author{
Aqeel Ahmad \\ Institute of Information Technology, Abottabad, Pakistan \\ Mohmad Yazam Sharif U \\ University Utara Malaysia Sintok, Kedah Darul Aman, Malaysia \\ Abdul Rashid Kausar \\ School of Business and Economics University of Management and Technology, Pakistan
}

Follow this and additional works at: https://ir.iba.edu.pk/businessreview

Part of the Human Resources Management Commons

\section{(c) (1)}

This work is licensed under a Creative Commons Attribution 4.0 International License.

\section{Recommended Citation}

Ahmad, A., Sharif U, M., \& Kausar, A. (2013). A comparative study of the HR professionals' effectiveness in the banking sector of Pakistan. Business Review, 8(2), 98-115. Retrieved from https://doi.org/10.54784/ 1990-6587.1289

This article is brought to you by iRepository for open access under the Creative Commons Attribution 4.0 License and is available at https://ir.iba.edu.pk/businessreview/vol8/iss2/8. For more information, please contact irepository@iba.edu.pk. 


\title{
ARTICLE
}

\section{A Comparative Study of the HR Professionals' Effectiveness in the Banking Sector of Pakistan}

\author{
Aqeel Ahmad \\ COMSATS \\ Institute of Information Technology, Abottabad, Pakistan \\ Mohmad Yazam Sharif \\ University Utara Malaysia \\ Sintok, Kedah Darul Aman, Malaysia \\ Abdul Rashid Kausar \\ School of Business and Economics \\ University of Management and Technology, Pakistan
}

\begin{abstract}
The aim of this study is to examine the relationship of human resource (HR) professionals' competencies, HR professionals' willingness (HRPW) and HR professionals' effectiveness (HRPE). The Human Resource Competency Study model is used in this research, which is modified to include 'Willingness' as an important competency. The study is undertaken using data drawn from the line managers of two large Privatized Banks (PB1) and (PB2) of Pakistan. It is hypothesized that all HR professionals' competencies are equally and strongly related to HR professionals' effectiveness which is theoretically associated with organizational performance. The study finds that the HR professionals' competencies including HR social competencies (HRSC), HR technical competencies (HRTC) and HRPW have a highly significant correlation with HRPE. However, social competencies are more significant in their relationship with HRPE than the HRTC and HRPW in both PB1 and PB2. Within the sub competencies of HRSC the 'Credible Activist' (in case of PBP1) is the most significant and strongly correlated competency with HRPE. While, the 'Culture and Change Steward' (in case of PB2) is the most significant and strongly correlated competency with HRPE. Furthermore, within the sub competencies of HRTC the 'Operational Executor' (in case of PB1) and 'Business Ally' (in case of PB2) have a stronger relationship with HRPE than others. The study finds the HR professionals' competencies are lacking in the PB1 in Pakistan as most of the HR professionals' competencies as well as their effectiveness were found to be below the expectation levels of the line managers. The study also finds the HR professionals' competencies, willingness and effectiveness are generally on moderating side (in case of PB2). This indicates that the HR professionals' competencies, willingness and their effectiveness need to be improved further which will ultimately lead to the better organizational performance.
\end{abstract}

Keywords: HR Professionals’ Competencies, HR Professionals’ Effectiveness, Willingness, Bank 


\section{Introduction}

Due to an economic shift from agriculture to industrial to services and now to information, the role of the human resource (HR) function in organizations has changed. HR has become central to business competitiveness. By virtue of the multiple managerial roles, the HR function has become strategic, operational, as well as process and people oriented (Lemmergaard, 2009). In the past HR was considered to be a staff function where its role was considered as an administrative and HR operations were often regarded as a commodity. It has all changed and in recent time HR's primary role is to influence workforce mindset, skill-set and work-related behavior for formulation and implementation of organizational strategies and the alignment of Human Resource management (HRM) with the strategic needs of an organization (Beatty, et al., 2003; Bal, 2011).

In the new era of $21^{\text {st }}$ century, the HRM function is experiencing unprecedented changes. Lawler and Mohrman (2003) argue that human resources are emerging as one of the key resource within the organizations. This paradigm shift in resources concerning the value of human resources will, therefore, generate new opportunities for the HR function and would help to develop a broader role in the organization's operation. Ulrich et al., (2009) have reiterated that business challenges have become more complex because of globalization of markets, products and services. The changes in information and communication technology have also created more competition because of customers and suppliers' awareness and thus demand higher level of skilled workforce in the organization. Furthermore, this dynamism is occurring in an environment where products, markets and services are highly globalized. Therefore, giving a major impetus to the need to bring about changes in the required skill and capabilities set of the organization's HR. In other words the effect of this setting of changing environment, shifting competitive landscape enjoin upon the organizations to seek to develop new competencies and HRM practices as well as the modify the role of HR professionals from functional to strategic partners.

The purpose of this paper is first, to understand the relationship between HR professionals' competencies with HR professionals' effectiveness. Secondly, the paper investigate those competencies which the employees observe as the most significant and will require immediate attention. The paper has made the choice to seek perception of employees with regard to competencies derived from the Ulrich et al., (2007) model. The choice of this study is the banking sector of Pakistan. This sector is significant in view of its current growth potential. Further, over the past decade the reforms initiated by State Bank of Pakistan (SBP) have identified the lack of competencies of HR professionals' as an obstacle in the face of growth potential of the banking sector.

\section{Banking Sector of Pakistan and Human Resource Management}

Researchers have claimed that in the $21^{\text {st }}$ century, the banking sector will play a critical role in the economic wellbeing not only of the country but the world. Khan (2004) suggest that the banking sector is one of the most sensitive businesses all over the world and plays a significant role in a contemporary world of money and economy of any country (Bollard et al., 2011) and Pakistan is no exemption. To be more explicit about the role a banking sector plays in their economy Abbas and Malik (2010) suggest that banking sector of an economy generally perform three roles which include the facilitation of payment system, mobilization of savings, and allocation of funds to stakeholders like government, investors, consumers, and business community who can utilize them for the generation of economic activities. On the other hand, 
Rehman (2011) reports that banks indulge in catering to the needs of government, public sector organization and private businesses. All the above lead us to conclude that the banking sector, therefore, plays a vital role in the developmental activities in terms of offering financial resources to the public and private sector for achieving the developmental goals.

HRM has not been well-established in the banking sector of Pakistan even though Khan (2004) states that Pakistan has a well developed banking system. The SBP (2008) mentioned its report that the bankers believe the incompetent of HR professionals is the major barrier for growth of the Pakistani financial sector. Mangi et al., (2012) report that HR professionals are not capable to develop or perform good HR practices which eventually leads to the employees' dissatisfaction and they are unable to perform what is expected from them. There is enough room for banks to improve cost efficiency, which can be acquired by corrective measures to improve further HRM practices, best choice for asset portfolio and reducing in Non-performing loans (Bukhari, 2008; Abbas \& Malik, 2010; Khan et al., 2011).

Table 1: Non-Performing Loans of PB1 and PB2 of Pakistan

\begin{tabular}{lccccc}
\multicolumn{5}{c}{ (NPLs in Rupees Billion) } \\
\hline Years & 2006 & 2007 & 2008 & 2009 & 2010 \\
\hline $\begin{array}{l}\text { Non-Performing Loans } \\
\text { (PB1) }\end{array}$ & 26.92 & 24.59 & 36.08 & 42.30 & 44.80 \\
$\begin{array}{l}\text { Non-Performing Loans } \\
\text { (PB2) }\end{array}$ & 8.57 & 10.73 & 18.27 & 23.24 & 23.90 \\
\hline
\end{tabular}

Source: Economic Bulletin (2011)

The data shows (Table 1) that the Non-Performing Loans (NPLs) in term of percentage have been growing in large leading Private Banks (PB1 and PB2) in Pakistan. From the last few years the NPLs is increasing attention in Pakistan and also the hampering the profitability of the banks. High amount of NPLs in the banking sector of Pakistan is attributed to the ineffectiveness of HR professionals and needs to be investigated (Hussain, 2008). This attribute to the HR practices including hiring of managers on political basis and under the influence of those forces which provided them the job to the detriment of professionalism, poor customer services and a high bureaucratic approach which leads to inefficiency of Pakistani banking sector (Ahmad et al., 2012). On the other hand, Janjua and Malik (2011) argue that banks reduce their NPLs through improve their HRM effectiveness. The HR professional is responsible for employee's performance because he is involved in recruiting, retaining and rewarding. While, Reilly (2012) suggest being competent HR professionals they need greater emphasis on hiring the right talent in place to overcome the obstacles of the business performance. If performance of the bank officers has to be improved as required by strategic consideration of banking sector in Pakistan to reduce NPLs, it has a relevance and relationship with HR professionals' competencies and their professionals' effectiveness.

\section{Significance of the Study}

This study attempts to provide new insights into the body of knowledge and practice of HR professionals' competencies in the banking sector of Pakistan. HR professionals' competencies in the banking sector still require improvement in Pakistan which can enable them to hire, develop, motivate and retain the employees. These employees when properly trained and 
motivated can help to lend money prudently and reduce the NPLs effect successfully. These improvements in HR practices will help the Pakistani economy, which is suffering from many other political \& security challenges. It can eventually result in helping Pakistan stand on its own feet financially. This study may also be taken as a benchmark for the banking sector of other developing countries like Bangladesh and Sri Lanka. Moreover, this study will be a significant initiative in the development of the HRM as a profession in developing countries like Pakistan and as such will contribute to the HRM body of knowledge of Pakistan and especially of South Asian Association for Regional Co-operation (SAARC) ${ }^{1}$ and Developing-8 (D-8) ${ }^{2}$ countries because of similar economic development indicators. Finally, results of this study on HR professionals' effectiveness can relate to the improvement of the banking performance and the overall economic development of Pakistan.

\section{Literature Review}

The area of HRM has passed through a long path from its humble beginning. The historical trends of the HRM can be seen from various perspectives such as the development of HRM as professionals and scientific discipline as an aid to management, as a political and economic conflict between management and workers and as a growing movement of workers' involvement which is influenced by developments in industrial and social psychology (Schuler, 1992; Pucik, 1996; Francis \& Kegan, 2006).

\section{HR Professionals' Effectiveness}

Many scholars argue that the HRM effectiveness is a very vast construct. Many studies on HRM effectiveness highlighted that, how HR professionals doing their job in the organization and how their functions aligned to foresee the organizational performance (Huselid, 1995; Boxall, 1996; Baron \& Kreps, 1999; Wright et al., 2001). To evaluate the HRM effectiveness started with the research of Tsui (1984) and recommended that the structure of personnel department effectiveness need to be examine. Rastogi and Dave (2004) argue that effectiveness is best seen as something the HR professionals create from a situation. Moreover, he meets the goals in every share of the activities of organizations. Currently effectiveness of HRM is a critical component in the development process of developing countries. Although, HRM has come under strong criticism in many developing countries with their effectiveness thrown into significant reservation (Bennell, 1994; Budhwar, 2001; Praha, 2004; World Bank, 1994).

Kane and Crawford (1999) reported that one of the barriers of effective HRM is the lack of competent HR staff. The staff of HR department is trying to find out the ways to contribute their organizations efficiently and effectively. Ruel et al., (2007) Emphasis that the basic factor for HR staff to be effective he or she should be competent then they can contribute for and add value to the organizations. The effectiveness of HRM is frequently talked about as HRM's contribution to an organization's output. The HR professional's competencies and their effectiveness have not been thoroughly studied in South Asia. Han, et al., (2006) argued that HRM as a management field is in its relatively early stages in Asia compared to the western countries. They have focused on various issues such as measuring the managerial effectiveness, examining the process of ensuring managerial effectiveness and building models of managerial effectiveness (Sharif et al., 2011). On the other hand, Shehzad (2010) argues effective HR department should

${ }_{1}^{1}$ Afghanistan, Bangladesh, Bhutan, India, Maldives, Nepal, Pakistan, Sri Lanka

${ }^{2}$ Bangladesh, Egypt, Indonesia, Iran, Malaysia, Nigeria, Pakistan, Turkey 
have the essential HR competencies to enhance the level of success and competitive advantage. Guest and Conway (2011) report that HR professionals' effectiveness even more important than the HR practices. HR professionals' competency is a necessary first step towards the HR professionals' effectiveness.

\section{HR PROFESSIONALS' COMPETENCIES}

Literature on competencies has expanded rapidly in the last two decades (Hollenbeck et al., 2006; Bartram, 2005; Hamel \& Prahalad 1998; Boyatzis, 1982). Kurz and Bartram (2002) explain that competency is not a performance itself, but a list of capabilities, actions, procedures and responses available that facilitates a range of work demands to be met effectively by some employees better than others. Competencies are employees' personal characteristics, (knowledge, skills, behavior, attitude, aptitudes, and social motives) that are linked to effective and advanced performance in a job (Gangani et al., 2006; Dubois \& Rothwell, 2004; Boyatizis, 1982). Ulrich et al., (2008) argue that competencies refer to the knowledge, skills and behaviors demonstrated by individuals in the course of getting their work done.

\section{MODELS OF HR COMPETENCIES}

Many surveys have been conducted around the globe on HR competencies and some notable ones are presented below in Table 2.

Table 2: HR Competencies

\begin{tabular}{|c|c|c|c|}
\hline Sr. \# & Name of Authors & Years & HR Competencies \\
\hline 1. & Kesler & 1995 & $\begin{array}{l}\text { Performance Capabilities, HR Technical } \\
\text { Know-How and Business Know-How. }\end{array}$ \\
\hline 2. & $\begin{array}{l}\text { Yeung, Woolcock and } \\
\text { Sullivan }\end{array}$ & 1996 & $\begin{array}{l}\text { Core, leadership, HR expertise and } \\
\text { Consultation. }\end{array}$ \\
\hline 3. & $\begin{array}{l}\text { US office of Personnel } \\
\text { Management }\end{array}$ & 1999 & $\begin{array}{l}\text { Leadership, HR expertise, Consultation } \\
\text { and Core. }\end{array}$ \\
\hline 4. & $\begin{array}{l}\text { World Federation of } \\
\text { Personnel } \\
\text { Management Associations }\end{array}$ & 2000 & $\begin{array}{l}\text { Individual style, organizational } \\
\text { involvement, leadership and technical } \\
\text { activities. }\end{array}$ \\
\hline 5. & Schuler and Jackson & 2001 & $\begin{array}{l}\text { Business competency, Leadership and } \\
\text { Managerial competencies, Change \& } \\
\text { knowledge management competencies } \\
\text { and Professional and technical } \\
\text { competencies. }\end{array}$ \\
\hline 6. & Schoonover & 2003 & $\begin{array}{l}\text { Personal Attributes, Leadership \& } \\
\text { Management Competencies, HR Core } \\
\text { Competencies and HR Role-Specific } \\
\text { Competencies. }\end{array}$ \\
\hline 8. & Boyatzis & 2008 & $\begin{array}{l}\text { Expertise \& experience, knowledge and } \\
\text { cognitive }\end{array}$ \\
\hline
\end{tabular}




\section{Hr Competency Model}

Ulrich (2007) and his colleagues has suggested six competencies domains as credible activist, cultural and change steward, talent manager/organization designer, strategic architect, business ally, and operational executor. This model is latest and more relevant to the current business environment and is directly related with the HR professionals in the $21^{\text {st }}$ century. We look at HR professional competencies through the lens of Ulrich et al., (2007) model. The competency constructs divided / broken into social-based and technical-based competencies. The HR professional's competency model is depicted in Figure 2.

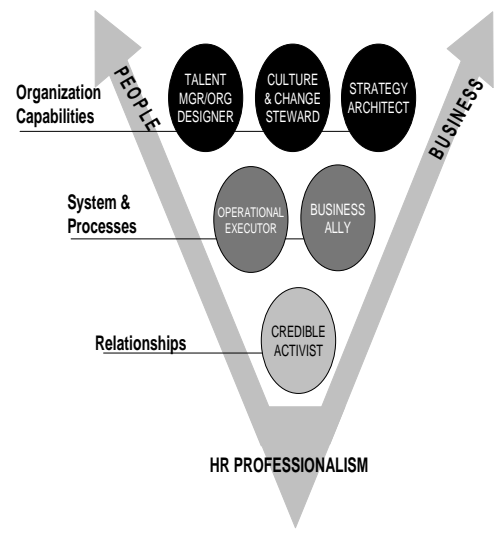

Figure 2: HR Competency Model by Ulrich et al., (2007)

\section{Credible Activist}

According to Grossman (2007) credible activist competency is the top indicator of HR professional performance. This competency is the heart of what is takes to be an effective HR professional. Ulrich et al., (2008) argues that the HR professional needs to be both credible (respected, admired, listened to) and active (offers a point of view, takes a challenges assumptions).

\section{Talent Manager / Organization Designer}

Attracting, developing and retaining talent are the most eminent functions of $\mathrm{HR}$ professional. According to Ulrich et al., (2008) the most effective HR professional those are master of both talent manager and organization designer. Talent management focuses on competency requirements and how individuals enter and move up, across, or out of the organization. Organization design more focuses on how an organization incorporates capability into the structure, processes, and policies that shape how an organization works.

\section{Culture \& Change Steward}

Culture and change became a common buzzword in late $20^{\text {th }}$ century. The 1980 s and 1990s brought a dramatic era of downsizing, mergers, acquisitions, and restructure for many organizations. Culture \& change has been acknowledged as an important influential factor in examine performance of the organizations (Wilkins \& Ouchi, 1983; Marcoulides \& Heck, 1993). Ulrich et al., (2008) argues culture has been important feature in HR competency studies since 
1997. HR professionals need to recognize, articulate and help shape an organization's culture to make change happen. Culture is a pattern of activities more than a single event. As steward of culture, HR professionals respect those aspects of the past culture that should be respected, at the same time helping to shape a new culture that will facilitate organization success.

\section{Strategy Architect}

Lawler and Mohrman (2003) found that HR professionals who have desired to be strategic partners must have understanding of business strategy and ways to support its implementation. Ulrich et al., (2009) argues HR professionals must thoroughly master the strategic architecture of the business in which they work. The need an in-depth appreciation of the business portfolio and what makes each business distinctive in customers' eyes. HR professionals must understand the business strategy and align HR practices with it. This includes being able to identify the problems central to the business strategy, recognize marketplace trends and their impact on the business, and translate the strategic direction into annual business and HR initiatives.

\section{Business Ally}

Business related competencies enable HR professional to understand how business considerations unique to a firm can create firm-specific HRM needs (Schuler, 1992; Walker, 1992). While Heffernan and Flood (2000) reports that one new and emerging human resource theme is that competencies and effectively performs their HR practices in helping organizations cope with the changing environment and need to integrate and organization's HR strategy and its business strategy. According to Caudron (2003) business knowledge is considered extremely very important for HR professional. Ulrich and Brockbank (2005) stated that HR professionals master the knowledge of external realities of today's business environments. They must be fully literate how they can add value for their investors, commercial customers, internal customers like managers and employees. Therefore HR professionals are required to become active players and partners of business and develop human abilities and organizational capabilities that enable an organization to compete now and in the future.

\section{Operational Executor}

Not too many years ago, day-to-day activities and policy issues were the prime responsibility of the "personnel" department. Personnel department manage the paperwork, employee hiring, firing, paying and promoting. Operational implementation was the name of the game. The personnel department emphasized by focusing on the terms and conditions of work and running the administrative systems to assist the employee to perform their duty properly (Ulrich et al., 2008). HR professional as an operational executor is responsible for HR procedures need to be documented and implemented. HR professional's competency as an operational executor to carry out the operational aspects of managing employee and organization. In addition, employees need to be hired, trained and paid etc. HR professional is accountable to make sure that these fundamental needs are efficiently met (Ulrich et al., 2009).

\section{Hr Professionals' Willingness}

The word 'Will' is associated with intrinsic motivation to be effective or not. Smith and McLaughlin (2004) argue that if 'will' is combined with employees' competencies and capabilities, then personal performance will go up. If HR professionals lack the willingness and 
motivation to contribute their knowledge and expertise, then he may not be effective. One way by which HR department can add value to the organization is that HR professionals be willing to actively contribute to HRM strategies and their implementation. This paper plan to examine the effect of willingness on the HR professionals' effectiveness.

\section{Relationship between Hr Professionals' Competencies, Hr Professionals' Willingness and Hr Professionals' Effectiveness}

The research of Whittaker and Marchington (2003) reports that line manager express their concern that lack of willingness from HR professionals during the executing of an HR practices can affect their overall effectiveness. Huselid (1995) argues that willingness is a necessary condition to perform effectively. He advocates that the performance of even the best employees will decrease if they are not willing / motivated to perform their duties. HR professional may / can perform effectively if they are competent and willing. According to Brockbank (1999) HR professional have to obtain the competencies if they desire / willing to become highly effective. While Ulrich and Grochowski (2012) claim that HR professionals' willingness is one of the best ways to make the HR professional effective. The one way a human resource department can add value for the organization, if HR professionals be willing to actively contribute to HRM strategies implementation. HR professional be willing to actively develop the skills set they need in order to become effective.

\section{Theoretical Framework}

The research model shown in Figure 3 includes the three following predictors to assess and their impact on HR professionals' effectiveness: HR professionals' social competencies, HR professionals' technical competencies and HR professionals' willingness. HR professionals' effectiveness ratings would be collected from line managers. Since these groups were the internal HR customers, they were believed to be the right people and the knowledgeable people with the most to say about HR professionals’ effectiveness.

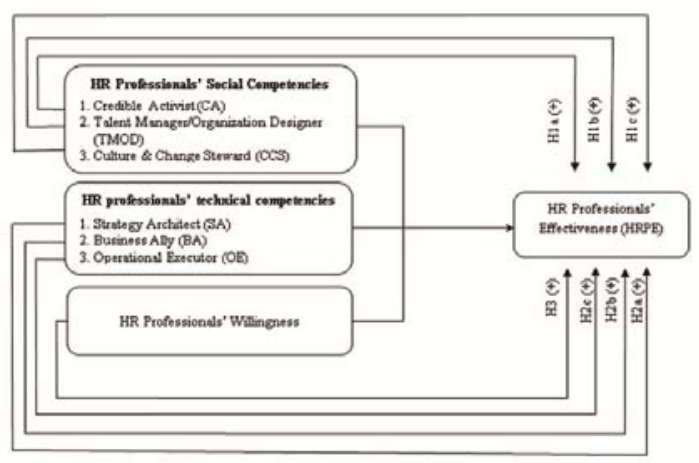

Figure 4: Research Model for Present Study

Based on the above theoretical model the following hypotheses are proposed.

Hypothesis 1: HR professionals’ social competencies (H1) as defined CA (H1a), TMOD (H1b) \& CCS (H1c) have a positive relationship with HR professionals' effectiveness as perceived by line managers. 
Hypothesis 2: HR professionals' technical competencies (H2) as defined by SA (H2a), BA (H2b) \& OE (H2c) have a positive relationship with HR professionals' effectiveness as perceived by line managers.

Hypothesis 3: HR professionals' willingness has a positively relationship with HR professionals' effectiveness as perceived by line managers.

\section{Data Collection And Analysis}

A cross sectional survey method is used for the present study and the questionnaire used draws on the previous researches (Sharif \& Ahmad, 2009; Ulrich et al., 2007 and Han et al., 2006) and is adapted through appropriate modification to align with the Pakistani context which helps establish the ecological validity and reliability of the instrument. The questionnaire is make up of three parts namely; Part I) Personal information of the respondents and background section with 5 items; Part II) The HR professionals' effectiveness as perceived by the line managers and contains 11 items; Part III) HR professionals’ competencies and HR professionals’ willingness as perceived by the line managers comprise of total 65 items. The survey questionnaire was distributed using snowballing technique with the respondents being the individual manager (permanent full time) in two large local privatized banks in Pakistan. Before sending the final draft of the questionnaire, a pilot test was conducted to ensure the reliability and validity of the content measurement scale. Therefore, the overall Cronbach Alpha of the instrument is 0.985 and the entire scale variables used in the research instrument fall within acceptable limits.

\section{Respondents Profile for the Study}

This section describes the demographics of the respondents who participated in this study. The individual characteristics of the respondents such as designation, educational qualification, age, years working in the banking sector and gender are presented in Table 3 below.

Table 3: Profile of the Respondents

\begin{tabular}{|c|c|c|c|c|c|}
\hline Variables & Category & $\begin{array}{c}\text { Frequency } \\
(\mathrm{PB} 1)\end{array}$ & $\begin{array}{c}\text { Percentage } \\
(\mathrm{PB} 1)\end{array}$ & $\begin{array}{c}\text { Frequency } \\
(\mathrm{PB} 2)\end{array}$ & $\begin{array}{c}\text { Percentage } \\
\text { (PB2) }\end{array}$ \\
\hline Designation & $\begin{array}{l}\text { Branch Manager } \\
\text { Operations Manager } \\
\text { Customer Relations } \\
\text { Manager } \\
\text { Credit Manager }\end{array}$ & $\begin{array}{l}10 \\
12 \\
5 \\
3\end{array}$ & $\begin{array}{l}33.3 \\
40.0 \\
16.7 \\
10.0\end{array}$ & $\begin{array}{c}15 \\
16 \\
7 \\
9\end{array}$ & $\begin{array}{l}31.9 \\
34.0 \\
14.9 \\
19.1\end{array}$ \\
\hline $\begin{array}{c}\text { Highest } \\
\text { Qualification }\end{array}$ & $\begin{array}{l}\text { MS/M. Phil } \\
\text { Masters } \\
\text { Bachelor }\end{array}$ & $\begin{array}{c}3 \\
23 \\
4\end{array}$ & $\begin{array}{l}10.0 \\
76.7 \\
13.3\end{array}$ & $\begin{array}{c}1 \\
35 \\
11\end{array}$ & $\begin{array}{l}2.1 \\
74.5 \\
23.4\end{array}$ \\
\hline Age & $\begin{array}{l}\text { Less than } 30 \text { Years } \\
30-40 \text { Years } \\
41-50 \text { Years } \\
\text { More than } 50 \text { Years }\end{array}$ & $\begin{array}{c}4 \\
8 \\
7 \\
11\end{array}$ & $\begin{array}{l}13.3 \\
26.7 \\
23.3 \\
36.7\end{array}$ & $\begin{array}{c}12 \\
28 \\
5 \\
2\end{array}$ & $\begin{array}{l}25.5 \\
59.6 \\
10.6 \\
4.3\end{array}$ \\
\hline $\begin{array}{c}\text { Years Working in } \\
\text { the } \\
\text { Banking Sector }\end{array}$ & $\begin{array}{l}\text { 1-3 Years } \\
\text { 4-6 Years } \\
\text { 7-10 Years } \\
\text { 11-15 Years } \\
\text { More than } 15 \text { Years }\end{array}$ & $\begin{array}{c}2 \\
2 \\
6 \\
4 \\
16\end{array}$ & $\begin{array}{c}6.7 \\
6.7 \\
20.0 \\
13.3 \\
53.3\end{array}$ & $\begin{array}{c}6 \\
15 \\
16 \\
5 \\
5\end{array}$ & $\begin{array}{l}12.8 \\
31.9 \\
34.0 \\
10.6 \\
10.6\end{array}$ \\
\hline Gender & $\begin{array}{l}\text { Male } \\
\text { Female }\end{array}$ & $\begin{array}{c}24 \\
6\end{array}$ & $\begin{array}{l}80.0 \\
20.0\end{array}$ & $\begin{array}{l}33 \\
14\end{array}$ & $\begin{array}{l}70.2 \\
29.8\end{array}$ \\
\hline
\end{tabular}


Most of the respondents (40\% and $34 \%$ ) are Operations Managers of PB1 and PB2 respectively. They are responsible for managing the day to day affairs in their branch, (33 \% PB1 and $32 \%$ PB2) are the Branch Managers. Customer Relation Managers as well as Credit Managers accounted for $16.7 \%$ and $10.0 \%$ respectively in PB1. In case of PB2 the Credit Managers are $19 \%$ and Customer Relation Managers are $15 \%$. With respect to the respondent age in PB1, majority that is $36.7 \%$ of the respondents are more than 50 years of age while those between 30 to 40 years of age are $26.7 \%$ and between 41 to 50 and less than 30 years are $23.3 \%$ and $13.3 \%$ respectively. In case of PB2 the majority that is $59 \%$ of the respondents are between 30 to 40 years while those who are less than 30 are $25 \%$ and between 41 to 50 and more than 50 years are $16 \%$ and $4 \%$ respectively. In PB1 $53.3 \%$ respondents have more than 15 years work experience in the banking sector and $20 \%$ have served for 7 - 10 years while those between 11 to 15 years working experience are $13.3 \%$. On the other hand, in PB2 $34 \%$ respondents have between 7 to 10 years work experience in the banking sector and $32 \%$ have served for $4-6$ years while those between 1-3 years working experience are $13 \%$ and 11 to 15 and more than 15 years working experience are 10 . \% each respectively. Further as far as educational qualifications are concerned, almost $76.7 \%$ of the respondents have a 'Master' degree with the remaining $13.3 \%$ and $10 \%$ hold Bachelor and MS/M. Phil degrees respectively. This reflects that highly educated people participated in this survey. $\quad 80 \%$ of the respondents are Male while $20 \%$ are Female respondents showing a good mix of gender contribution in the survey.

Table 4 shows the mean score and indicates the extent of respondent's agreement level with the various competencies constructs. The variables that underline the constructs are measured on a five point Likert scale of $1-5$, where 1 represents "Strongly Disagree" and 5 "Strongly Agree". In this regard, any mean scores for the constructs that are below the midpoint (3.00) is considered by the respondents to be low and reflects a weakness in that competence.

Mean scores between 3.00 to 3.50 can be seen as indication of moderate level of competence, and the mean scores above 4.00 to 5.00 can be considered as an indication of strength in the competence area as perceived by the responding managers.

Table 4: Descriptive Statistics of the Variables

\begin{tabular}{|c|c|c|c|c|}
\hline Constructs & $\begin{array}{c}\text { Mean } \\
\text { PB1 }\end{array}$ & $\begin{array}{c}\text { Standard } \\
\text { Deviation }\end{array}$ & $\begin{array}{c}\text { Mean } \\
\text { PB2 }\end{array}$ & $\begin{array}{c}\text { Standard } \\
\text { Deviation }\end{array}$ \\
\hline HR Professionals’ Effectiveness (HRPE) & 2.56 & .734 & 3.02 & .673 \\
\hline Credible Activist (CA) & 2.89 & .688 & 3.09 & .614 \\
\hline Talent Manager /Organization Designer (TMOD) & 2.82 & .623 & 3.14 & .694 \\
\hline Culture and Change Steward (CCS) & 2.93 & .650 & 3.09 & .779 \\
\hline Strategy Architect (SA) & 2.74 & .739 & 3.13 & .762 \\
\hline Business Ally (BA) & 2.77 & .765 & 3.37 & .753 \\
\hline Operational Executor (OE) & 3.08 & .645 & 3.21 & .741 \\
\hline HR Professionals’ Willingness (HRPW) & 2.84 & .874 & 3.35 & .685 \\
\hline
\end{tabular}

Table 4 shows that the highest mean scores of PB1 is (3.08) for OE competency as considered by the respondents, thus indicating that the competency of OE is moderately present in the HR professionals'. On the other hand, there seems to be a general perception among the respondents that HR professionals' lack in the other required competencies (CA, TMOD, CCS, $\mathrm{SA}$ and BA). A similar low opinion is prevalent among the respondent regarding the effectiveness of the HR professionals'. This result may be considered surprising given the highly developed financial sector but seems to be in line with prior research, where HR professionals' competencies have been reported to be of low level (SBP, 2008; Ejaz, 2009; Mangi et al., 2012). The respondents on the other hands seem to also consider that the HR professionals' are 'unwilling' to 
either acquire competencies or apply these competencies to help the organization to effectively implement strategies.

Table 4 show that the highest mean scores is (3.37) for BA as considered by the respondents, thus indicating that the competency of BA is moderately present in the HR professionals in the PB2. On the other hand, there seems to be a general perception among the respondents that HR professionals' are on the moderately have these competencies (CA, TMOD, CCS, SA, OE, HRPW and HRPE) in PB2.

Given that HR professionals' score low (in case of PB1) on both their competencies and their effectiveness in the perceptions of the responding managers, a case can be made that there is a suggestive relationship between HR professionals' effectiveness and HR professionals' competencies. This proposition finds support from Ulrich et al., (2012). However, this aspect is further explored through correlation analysis, which also forms part of the hypotheses testing framwork.

\section{Correlation Analysis}

The Table 5 addresses the relationship between HR Professionals Social Competencies (HRSC) with sub constructs Credible Activist (CA), Talent Manager/Organization Designer (TMOD) and Culture and Change Steward (CCS), HR Professionals' Technical Competencies (HRTC) with sub constructs; Strategy Architect (SA), Business Ally (BA) and Operational Executor (OE) and HR Professionals' Willingness (HRPW) with HR Professionals' Effectiveness (HRPE). The hypotheses (H1 - H3) and are analyzed using Pearson Correlation.

Table 5: Relationship of HRSC, HRTC, HRPW with the HRPE of PB1

\begin{tabular}{|c|c|c|c|c|c|c|c|c|c|c|c|}
\hline & Variables & HRPE & CA & TMOD & CCS & HRSC & SA & $\mathrm{BA}$ & $\mathrm{OE}$ & HRTC & $\begin{array}{c}\text { HRP } \\
\text { W }\end{array}$ \\
\hline \multirow{5}{*}{$\begin{array}{l}\text { Dependent } \\
\text { Variable }\end{array}$} & HRPE & 1 & & & & & & & & & \\
\hline & CA & $.801^{* *}$ & 1 & & & & & & & & \\
\hline & TMOD & $.640 * *$ & $.730 * *$ & 1 & & & & & & & \\
\hline & CCS & $.577 * *$ & $.662 * *$ & $.749^{* *}$ & 1 & & & & & & \\
\hline & HRSC & $.753^{* *}$ & $.894 * *$ & $.923 * *$ & $.880 * *$ & 1 & & & & & \\
\hline Independen & SA & $.531^{* *}$ & $.596^{* *}$ & $.620 * *$ & $.636^{* *}$ & $.685^{* *}$ & 1 & & & & \\
\hline \multirow{4}{*}{ t Variables } & $\mathrm{BA}$ & $.597 * *$ & $.644^{* *}$ & $.666^{* *}$ & $.754 * *$ & $.760 * *$ & $.896^{* *}$ & 1 & & & \\
\hline & $\mathrm{OE}$ & $.611^{* *}$ & $.644 * *$ & $.660 * *$ & $.482 * *$ & $.669 * *$ & $.578 * *$ & $.567 * *$ & 1 & & \\
\hline & HRTC & $.635^{* *}$ & $.691 * *$ & $.715^{* *}$ & $.713^{* *}$ & $.784 * *$ & $.955^{* *}$ & $.950 * *$ & $.742 * *$ & 1 & \\
\hline & HRPW & $.682^{* *}$ & $.675 * *$ & $.624 * *$ & $.603^{* *}$ & $.706^{* *}$ & $.768 * *$ & $.788 * *$ & $.736 * *$ & $.849 * *$ & 1 \\
\hline
\end{tabular}

**. Correlation is significant at the 0.01 level (2-tailed).

Table 6: Relationship of HRSC, HRTC, HRPW with the HRPE of PB2

\begin{tabular}{|c|c|c|c|c|c|c|c|c|c|c|c|}
\hline & Variables & HRPE & CA & TMOD & CCS & HRSC & SA & BA & $\mathrm{OE}$ & HRTC & HRPW \\
\hline \multirow{5}{*}{$\begin{array}{l}\text { Dependent } \\
\text { Variable }\end{array}$} & HRPE & 1 & & & & & & & & & \\
\hline & CA & $.728 * *$ & 1 & & & & & & & & \\
\hline & TMOD & $.700 * *$ & $.721 * *$ & 1 & & & & & & & \\
\hline & CCS & $.759 * *$ & $.626 * *$ & $.806 * *$ & 1 & & & & & & \\
\hline & HRSC & $.805 * *$ & $.854 * *$ & $.944 * *$ & $.904 * *$ & 1 & & & & & \\
\hline \multirow{5}{*}{$\begin{array}{c}\text { Independent } \\
\text { Variables }\end{array}$} & SA & $.668 * *$ & $.596 * *$ & $.674 * *$ & $.782 * *$ & $.760^{* * *}$ & 1 & & & & \\
\hline & BA & $.713^{* *}$ & $.682 * *$ & $.744 * *$ & $.764^{* *}$ & $.840 * *$ & $.759 * *$ & 1 & & & \\
\hline & $\mathrm{OE}$ & $.614^{* *}$ & $.730 * *$ & $.732 * *$ & $.649 * *$ & $.779 * *$ & $.493^{* *}$ & $.628 * *$ & 1 & & \\
\hline & HRTC & $.755^{* *}$ & $.755 * *$ & $.816 * *$ & $.848 * *$ & $.895 * *$ & $.898 * *$ & $.927 * *$ & $.765 * *$ & 1 & \\
\hline & HRPW & $.671^{* *}$ & $.796^{* *}$ & $.747 * *$ & $.686^{* *}$ & $.820 * *$ & $.680^{* *}$ & $.797 * *$ & $.751^{* *}$ & $.846^{* *}$ & 1 \\
\hline
\end{tabular}

**. Correlation is significant at the 0.01 level (2-tailed). 
As shown in Table 5 and Table 6 HRSC has a significant correlation at $0.753(\mathrm{p}<.000)$ $0.805(\mathrm{p}<.000)$ with the HRPE of PB1 and PB2 respectively. Within the sub competencies of HRSC, the CA is the most highly correlated at $0.801(\mathrm{p}<.000)$ with HRPE followed by TMOD at $0.640(\mathrm{p}<.000)$ and CCS at $0.577(\mathrm{p}<.000)$. In case of PB2 the sub competencies of HRSC, the CCS at $0.759(p<.000)$ is highly correlated with HRPE. We can further note that HRTC of PB1 and PB2 also has a significant correlation at $0.635(\mathrm{p}<.000) 0.755(\mathrm{p}<.000)$ with the HRPE respectively. On the other hand, within the sub competencies of HRTC, OE has the highest correlation at $0.611(\mathrm{p}<.000)$ among the sub constructs with the HRPE, (BA at $0.597(\mathrm{p}<.000)$ and SA at $0.531(\mathrm{p}<.003)$ respectively) of PB1. The highest correlation of sub competencies of HRTC in PB2 is BA 0.713 at $(\mathrm{p}<.000)$. SA $0.668(\mathrm{p}<.000)$ and OE $0.614(\mathrm{p}<.000)$ are also correlation with HRPE in PB2 respectively. Finally, we can observe that HRPW also is significantly correlated at $0.682(\mathrm{p}<.000)$ and 0.671 with the HRPE in PB1 and PB2 respectively. Given the above data there is significant support for the purposed hypotheses and as such we fail to reject them.

\section{Discussion}

The surveyed managers' of a two large privatized Pakistani banks perceive that competencies as defined by HR professionals' social competencies, HR professionals' technical competencies and HR professionals' willingness have a strong relationship with the HR professionals' effectiveness. We can observe this phenomenon from the evaluation done by managers of competencies and effectiveness (see Table 4) where both are considered below par in case of PB1. In other words they believe that as there is a lack of professionals' competencies the effectiveness of the function of HRM is also weak and not in line with what is expected or what is necessary to create successful organizational performance. The relationship between the effectiveness and the three competencies constructs are also supported by the results of correlation test (see Table 5). In other words, the general perception that all the Social and Technical Competencies are equally relevant and significant for professionals' effectiveness, is rejected as in the opinion of employees, 'social competencies' consider to more significantly relevant to HR professionals' effectiveness than the 'technical' or 'willingness' competencies. The rationale to understand this seeming anomaly comes from two points. In 'collectivist' societies (Hofstede et al., 1990) social relationships are more important than 'technical' which in turn are more significant for 'Individualistic' societies. Second, in the initial stages of introducing or developing a practice there is a strong need for interpersonal connectivity which will have a more profound impact on perceptions of effectiveness than those created by 'technical' aspects of competencies.

The surveyed managers' of PB2 perceive that competencies as defined by HR professionals' social competencies, HR professionals' technical competencies and HR professionals' willingness have a strong relationship with the HR professionals' effectiveness. We can observe this phenomenon from the evaluation done by managers of competencies and effectiveness (see Table 4) where both are considered at moderate level. In other words, they believe that as the HR professionals are on the moderate side. Still they are lack the competencies and can be improve further. The relationship between the effectiveness and the three competencies constructs are also supported by the results of correlation test (see Table 6). In other words, the general perception that all the social and technical competencies are equally relevant and significant for professionals' effectiveness, is rejected as in the opinion of employees, 'Social 
Competencies' consider to more significantly relevant to HR professionals' effectiveness than the 'technical' or 'willingness' competencies.

When seeking an answer to the research objective, where the question sought to understand, which of the sub constructs of competencies has a stronger relationship with HR professionals' effectiveness, we find that 'Credible Activist' (CA) is highly correlated with the HRPE in case of PB1. In other words, according to the surveyed managers, if, the HR professionals' are more 'Credible Activists', they will be more effective as professional. This finding is significant, as one would either expect all of the competencies to be valued at the same level in terms of their impact on professional effectiveness as proposed in the literature. In this regard one does not find any specific guide line in the Ulrich et al., (2007) model which may indicates if any of the sub competencies are more significant, than others, thus leading us to assume that they all are equally significant. On the other hand, as proposed by Lawler and Mohrman (2003) and Lawler and Boudreau (2009) the competency of strategic partners are highly desirable. Within the context of SHRM the 'strategic partner' competency relates to and highlights two sub competencies of the Ulrich et al., (2007) model and these are of 'Strategic Architect' and 'Business Ally' as both relate to the strategic partner concept. Thus one could consider either of the two to be more strongly related to effectiveness of HR professionals'. However, in the context of a developing economy of South Asia and in view of the argument provided above, CA being the most significant competency than all others is worth noting. This same proposition has been forwarded by Grossman (2007) also, who considers CA as the most important competency in terms of professionals' performance. Nevertheless, this relationship can be easily understood in the cultural context of South Asia, which according to Hofstede et al., (1990) is more 'collectivist'. In a collectivist framework dependence on others is a significant factor for performance. Therefore, HR Professionals' who are dependable, and are believed to do, what they say will do, will be considered more effective which is also the line taken by Brockbank et al., (2012). They also suggest that HR professionals' should do what they say they will do. It is important to note that according to us, HR professionals who are credible but not activist are admired but will produce little impact on performance. On the other hand, the HR professionals' who are activist but may not be credible, would not be able to garner enough trust in their abilities to implement required policies but those who are both activist and dependable will be the one with the most effective performance. The HR professionals thus need to focus on commitments in terms of being supportive of the organizational members and their efforts. Moreover, in all regions (US, Latin America, China, Australia and India) the CA competency is also seen as a positive contributor to bottom line result. Further the latest Human Resource Competency Study (HRCS) in 2012 also reports that CA is the more demanded competency required of HR professionals' for their effectiveness (Ulrich et al., 2012), thus lending support to the findings of this paper. On the other hand, we have already noted that HRTC has positive relationship with the HRPE. However, within the sub constructs of HRTC the 'Operational Executor' is the more significant in creating professionals' effectiveness the competency whose presence among HR professionals' are rated higher than all other (see Table 5). In other words, surveyed managers feel that day-to-day activities and policy implementation issues are very important for effective HR professionals'. This if seen from the point of view of CA being the most important competency, this perception become further clearer. To the authors it suggests that if professionals are dependable in implementing HR policies and practices they will be more effective, especially where operations are concerned. Reflects the overriding concern for 
implementing policies and may suggest a lagged affect of the Personnel Management era in managing human resource.

We have already indicated that HR professionals' effectiveness as an area of academic research is relatively at early stages most developing countries including Pakistan. In this ongoing work, this emerging area of research should be extended by including other private and public sector organizations. The result of this study can be used as a benchmark for other developing countries, which would need to cross cultural studies to assess and verify these findings.

\section{Conclusion}

The finding of this study contributes to the literature on the HR professionals' effectiveness. This study is the first of its kind to be undertaken in the two Pakistani privatized banks using competency based model of Ulrich et al., (2007) to understand HR professionals' effectiveness framework rather than HR practice based assessment. The study finds that the HR professionals' competencies including social, technical and willingness have a highly significant correlation with HR professionals' effectiveness. However, social competencies are more significant in their relationship with HR professionals' effectiveness than the other two i.e. HR professionals' technical competencies and HR professionals' willingness in both PB1 and PB2. Within the sub competencies of HR professionals' social competencies the 'Credible Activist' (in case of PB1) is the most significant and strongly correlated competency with HR professionals' effectiveness. While, the 'Culture and Change Steward' (in case of PB2) is the most significant and strongly correlated competency with HR professionals' effectiveness. Furthermore, within the sub competencies of HR professionals' technical competencies the 'Operational Executor' (in case of PB1) and 'Business Ally' (in case of PB2) have a stronger relationship with HR professionals' effectiveness than others. The study also finds the HR professionals' competencies are lacking in the PB1 in Pakistan as most of the HR professionals' competencies as well as their effectiveness were found to be below the expectation levels of the line managers. The study also finds the HR professionals' competencies, willingness and effectiveness are generally on moderating side (in case of PB2). This indicates that the HR professionals' competencies, willingness and their effectiveness need to be improved further which will ultimately lead to the better organizational performance. A professional value driven HR professional in the $21^{\text {st }}$ century should therefore, have the essential HR competencies as indicated by theoretical model to further enhance the level of their effectiveness. 茞

\section{References}

Abbas, K., \& Malik, M. H. (2010). Impact of Financial Liberalization and Deregulation on Banking Sector in Pakistan. Pakistan Institute of Development Economics; Working Paper 64. www.pide.org.pk/pdf/Working\%20Paper/WorkingPaper-64.pdf

Ahmad, A. Sharif, M. Y., \& Kausar, A. R. (2012). An Empirical Study of the HR Professionals' Effectiveness in the Largest Privatized Bank of Pakistan. Terengganu International Management and Business Journal, 2(2), 1-10.

Bal, Y. (2011). The new human resources management in the 21st century: a strategic view. Annual Conference on Innovations in Business \& Management, London, UK.

Baron, J.N., \& Kreps, D.M. (1999). Strategic Human Resource Resources. New York: John Wiley \& Sons. 
Bartram, D. (2005). The Great Eight Competencies: A criterion-centric approach to validation. Journal of applied Psychology, 90, 1185-1203.

Beatty, R.W., Huselid , M. A., \& Schneier, C.E. (2003). The New HR Metrics: Scoring on the Business Scorecard. Organizational Dynamics. New York: Free Press.

Bennell, P. (1994). Improving the Performance of the Public Sector in LDC: New Approaches to Human Resource Planning and Management, Occasional Paper no. 25, Geneva: ILO.

Bollard, A., Hunt, C. \& Hodgetts, B. (2011). The role of banks in the economy-improving the performance of the New Zealand banking system after the global financial crisis. Cross-cutting themes in economies with large banking system. Policy paper, IMF 2010.

Boxall, P. (1996). The Strategic HRM Debate and the Resource-based View of the firm. Human Resource Management Journal, 6(3), 59-75.

Boyatzis, R. E. (2008). Competencies in the 21st century. Journal of Management Development, 27 (1), 5-12

Boyatzis, R.E. (1982). The Competent Manager: A model for effective performance. New Your: Wiley \& Sons.

Brockbank, W., Ulrich, D., Younger, J., \& Ulrich, M. (2012). Recent Study Shows Impact of HR Competencies on Business Performance. Employment Relations Today. DOI 10.1002/ert. http://onlinelibrary.wiley.com/doi/10.1002/ert.21348/pdf

Brockbank, W. (1999). If HR Were Really Strategically Proactive: Present and Future Directions in HR'S Contribution to Competitive Advantage. Journal of Human Resource Management, 38(4), 337-352.

Budhwar, P.S. (2001). Human Resource Management in Developing Countries, London: Rutledge. 505-514.

Bukhari, Z.U. (2008). Key Antecedents of Organizational Citizenship Behavior in the Banking Sector of Pakistan. International Journal of Business and Management, 3 (12), 106-115.

Caudron, S. (2003). HR is Dead. Long live HR, Workforce, 82(1), 26-30.

Dubois, D. D., \& Rothwell, W. J. (2004). Competency-based Human Resource Management. Mountain View, CA: Davies-Black.

Ejaz, S. K., Ejaz, S. A., Rehman, K., \& Zaheer, A. (2009). Evaluating Effective Leadership Qualities of Managers in day-to-day Work of Banking Sector in Pakistan. International Journal of Management and Marketing Research, 2 (1), 103-111.

Francis, H. and Keegan, A. (2006) The changing face of HR: in search of balance, Human Resource Management Journal, Vol. 16, No. 3, pp.231- 249

Gangani, N., McLean, G. M., \& Braden, R. A. (2006). A Competency-based Human Resource Development Strategy. Performance improvement Quarterly, 19 (1), 127-139.

Grossman, R. J. (2007). New Competencies for HR. HR Magazine, 52 (6), 10-11. 
Guest, D., \& Conway, N. (2011). The impact of HR practices, HR effectiveness and a 'strong HR system' on organizational outcomes: a stakeholder perspective. The International Journal of Human Resource Management, 22(8), 1686-1702

Han, J., Chou, P., Chao, M., \& Wright, P. M. (2006). The HR Competencies HR Effectiveness Link: A Study in Taiwanese High-Tech. Human Resource Management, 45 (3) 391-406.

Hamel, G., \& Prahalad, C. K. (1998). Competing for the Future. Boston: Harvard Business School Press.

Heffernan, M. M., \& Flood, P.C. (2000). An exploration of the relationship between the adoption of managerial competencies, organizational characteristics, human resource sophistication and performance in Irish organizations. Journal of European Industrial

Training, 24 (2), 128-136.

Hofstede, G. Neuijen, B., Ohayv, D. D. \& Sanders, G. (1990). Measuring Organizational Cultures: A Qualitative and Quantitative Study Across Twenty Cases. Administrative Science Quarterly, 35, 286-316.

Hollenbeck, G. P., McCall, M. W., \& Silzer, R.F. (2006). Leadership Competency Models. Leadership Quarterly, 17(4), 398-413.

Hussain, I. (2008). Pakistan's Financial Sector: A Roadmap for 2005-2010 and Concept Paper for Strategic Plan. http://www.sbp.org.pk/about/Strategic_Plan_BOD.pdf.

Huselid, M. A. (1995). The Impact of Human Resource Management Practices on Turnover, Productivity, and Corporate Financial Performance. Academy of Management Journal, 38, 635672.

Janjua, M. A., \& Malik, M. H., (2011). The Cost Efficiency Analysis of Commercial Banks in Pakistan: Based on Free Distribution Approach. Pakistan Business Review, 694-714.

Kane, B., Crawford, J., \& Grant, D. (1999). Barriers to Effective HRM. International Journal of Manpower, 20 (8), 494-515.

Kesler, G. C. (1995). A Model and Process for Redesigning the HR Role, Competencies and Work in a Major Multi-national Corporation. Human Resource Management Journal, USA: University of Michigan.

Khan, M. A., Rehman, K., Rehman, I., Safwan, N., \& Ahmad, A. (2011). Modeling Link between Internal Service Quality in Human Resource Management and Employees Retention: A Case of Pakistani Privatized and Public Sector Banks. African Journal of Business Management, 5(3), 949-959.

Khan, M. H. (2004). Banking Industry of Pakistan: Performances and Constraints. http://www.mediamonitors.net/biopakbymukhkhan.html

Kurz, R., \& Bartram, D. (2002). Competency and Individual Performance: Modeling the World of Work In: I. T. Robertson, M. Callinan, \& D. Bartuam, D. (Eds). Organizational Effectiveness: The role of psychology, UK: John Wiley \& Sons, 227-255.

Lawler, E. E., \& Mohrman, S. A. (2003). Creating a strategic human resource organization: an assessment of trends and new directions. Stanford, CA: Stanford University Press. 
Lawler III, E. E. Boudreau, J. W. (2009). What makes HR a Strategic Partner? Center for Effective Organizations, Marshall School of Business, University of Southern California, Los Angeles, CA 90089-0871 http://ceo-marshall.usc.edu

Lemmergaard, L. (2009). From Administrative Expert to Strategic Partner. Employee Relations, 31 (2), 182-196.

Mangi, R. A., A. A., Shah, S. A. A., \& Ghumro, I. A. (2012). Human Resource Management Practices in Private Sector Organizations in Pakistan: Study of Culture Influences, Global Journal of Management and Business Research, 12 (7), 1-11.

Marcoulides, G. A., \& Heck, R. H. (1993). Organizational culture and performance: Proposing and testing a model. Organization Science, 4(2), 209-225.

Praha, K. (2004). African Wars and Ethnic Conflicts: Rebuilding Failed States. Human Development Report 2004 African Regional Background Paper UNDP. http://hdr.undp.org/en/reports/global/hdr2004/papers/HDR2004_Kwesi_Kwaa_Prah.pdf

Pucik, V. (1996). Strategic Alliances, Organizational Learning, and Competitive Advantage: The HRM Agenda, In: Knowledge Management and Organizational Design, P. S. Myers, (Ed.), pp. 151-165, Butterworth-Heinemann, ISBN 0-7506-9749-0, Boston, USA

Rastogi, R., \& Dave, V. (2004). Managerial Effectiveness: A function of personality type and organization.

http://www.thefreelibrary.com/Managerial+effectiveness\%3A+a+function+of+personality+type+a nd...a0119370586.

Rehman, U. W. (2011). Banking Reforms and Economic Growth : A Case Study of Pakistan. International Conference on Financial Management and Economics 11, (2011), IACSIT press Singapore.

Reilly, P. (2012). The practice of strategy. Strategic HR Review, 11 (3), 129-135.

Ruel, H. J. M., Bondarouk, T. V., \& Velde, M. V. (2007). The Contribution of e-HRM to HRM Effectiveness; Results from a Quantitative Study in a Dutch Ministry”. Employee Relation, 29 (3), 280-291.

SBP (2008). Banking Sector Reform: A Vision and Strategy for the Next 10 years, Lahore: Pakistani Press.

Schoonover, S. C. (2003). Human Resource Competencies for the new Century. www.schoonover.com

Schuler, R. S., \& Jackson, S. E. (2001). HR Roles, Competencies, Partnership and Structure. http://www.rci.rutgers.edu/ schuler/mainpages/SJ.htm.

Schuler, R. S. (1992). Strategic Human Resource Management: Linking People with the Needs of the Business. Organizational Dynamics, 21 (1), 18-32. 
Sharif, M. Y. Ahmad, A., \& Kausar, A. R. (2011). A Comparative Study on the Effectiveness of Human Resource Professionals in Pakistan and Malaysia. IBIMA Business Review, 1-11.

Shehzad, M. K. (2010). Keynote Address in Seminar on Collaboration of Banking Sector and Financial Institutions with NAB in Combating Corruption.

http://www.bis.org/review/r101013f.pdf

Smith, P.A.,C., \& McLaughlin, M. (2004). Knowledge Management: People are Important. Journal of Knowledge Management Practice.

Tsui, A. S. (1987). Defining the Activities and Effectiveness of the Human Resource Department: A multiple consistency approach. Human resource management, 26(1), 35-69.

Ulrich, D., Younger, J., Brockbank, W., \& Ulrich, M. (2012). HR Talent and the new HR competencies. Strategic HR Review, 11(4), 217-222.

Ulrich, D., \& Grochowski, J. (2012). From shared services to professionals services. Strategic HR Review, 11 (3), 136-142.

Ulrich, D., Allen, J., Brockbank, W., Younger, J., \& Nyman, M. (2009). HR Transformation: Building Human Resources from the Outside In. Boston: McGraw Hill.

Ulrich, D., Brockbank, W., Johnson, D., Sandholtz, K., \& Younger, J. (2008). HR Competencies: Mastery at the Intersection of People and Business, Virginia: Society for Human Resource Management.

Ulrich, D., Brockbank, W., Johnson, D., \& Younger, J. (2007). Human Resource Competencies: Responding to Increased Expectations. Inter Science. http://deepblue.lib.umich.edu/bitstream/2027.42/57368/1/20159_ftp.pdf,

Ulrich, D., \& Brockbank, W. (2005). The HR Value Proposition. Boston: Harvard Business School Press.

United States Office of Personnel Management, (1999). Looking to the Future: Human Resources Competencies: An Occupation in Transition. A Comprehensive Study of the Federal Human Resources Community.

Walker, J.W. (1992). Human Resource Strategy. New York: McGraw-Hill.

Whittaker, S., \& Marchington, M. (2003). Developing HR responsibility to the line: Threat, opportunity or partnership? Employee Relation, 25 (3), 245-261.

Wilkins, A. L., \& Ouchi, W.G. (1983). Efficient culture: Exploring the relationship between culture and organization performance. Administrative Science Quarterly, 28, 468-481.

World Bank, (1994). Adjustment in African: Reforms, Results, and the Road Ahead. A World Bank Policy Research Report, New York: Oxford University Press.

World Federation of Personnel management Association, (2000). HR Competencies and Professionals Standards. http://www.cpm-bk.ch/de/pdf/hr_competencies.pdf

Yeung, A., Woolcock, P., \& Sullivan, J. (1996). Identifying and Developing HR Competencies for the Future: Key to Sustaining the Transformation of HR Functions. The California strategic human resource partnership human resource planning, 19 (4), 48-58.

http://www.allbusiness.com/human-resources/596528-1.html 